clinic within 7 days of the referral. Previously the referral to diagnosis/treatment time was around 30 weeks, with patients waiting up to 18 weeks to be seen in secondary care. Initially the faecal calprotectin on the referral pathway was set at $50 \mu \mathrm{g} / \mathrm{g}$. Following triage by the IBD nurse the patients referred with a faecal calprotectin between $50-100 \mu \mathrm{g} / \mathrm{g}$ $(\mathrm{N}=100)$ were asked to repeat the stool sample.

Results The patients were reviewed and sent for investigation within 6 weeks of consultation with $56.5 \%$ of patients having endoscopic evaluation and only $28 \%$ of those patients received any diagnosis. When the faecal calprotectin cut off was raised to $100 \mu \mathrm{g} / \mathrm{g}$ the result then increased to $32 \%$ for IBD, with a further $17 \%$ with a differential diagnosis. The differentials included 3 colorectal cancers (not on 2WW), gynaecological problems, mesenteric panniculitis and $12.5 \%$ had microscopic colitis.

Conclusions The referral to diagnosis time was reduced from 30 weeks to on average 9 weeks. There were around 25 new referrals a month with patients being seen within 7 days. The IBD nurse is perfectly placed to triage and review suspected new patients improving patient experience as the waiting times are reduced and the IBD nurse was capable of identifying and managing differential diagnoses.

The challenge has been finding an optimum cut off for the faecal calprotectin so to eliminate low sensitivity and specificity for aiding diagnosis of IBD but also engaging with primary care colleagues to support the referral pathway.

It is recommended that the referral pathway is a suitable method for suspected IBD patients to be seen but that more education within primary care is required to improve patient experience and increase appropriate patient referrals.

\section{PTH-080 CLOSTRIDIUM DIFFICILE INFECTION IN PRE-EXISTING INFLAMMATORY BOWEL DISEASE: A CASE SERIES}

Iona Campbell ${ }^{*}$, Emily Brownson, Elaine Robertson. NHS Greater Glasgow And Clyde, UK

\subsection{6/gutjnl-2019-BSGAbstracts.139}

Introduction Inflammatory bowel disease (IBD) is a risk factor for clostridium difficile infection (CDI), and It is known that CDI in an IBD patient is associated with higher morbidity and mortality. It is thought that factors including alterations in the gut microbiome, mucosal disruption and immunosuppression provide a synergistic environment for CDI to complicate an IBD flare, yet there is no agreed consensus on best management of these patients.

Our aim is to examine a series of recent cases to assess our own practice and subsequent outcomes.

Methods A retrospective analysis was carried out of all cases of CDI in IBD patients in NHS GG\&C during 2018. Patients were identified via the regional CDI database; those with coexisting IBD were extrapolated.

Data collected included demographics, IBD subtype, and presence of other CDI risk factors. Severity of symptoms was assessed using Truelove \& Witts Criteria. Initial management, and any changes following the diagnosis of CDI were noted. Outcomes were measured by length of stay, survival to discharge and whether surgical intervention was required.

Results 14 patients in total were identified. 10 had a diagnosis of ulcerative colitis, 3 of Crohn's disease and 1 IBD unclassified. 11 of the 14 were on immunosuppressive therapy at the time of CDI ( 2 anti TNF; 1 thiopurine; 1 steroid; 7 5ASA) -

\begin{tabular}{|c|c|c|c|}
\hline Patient & Initial & Change 1 & Change 2 \\
\hline \multirow[t]{2}{*}{$1-3$} & Metronidazole & & \\
\hline & $400 \mathrm{mg}$ TDS & & \\
\hline \multirow[t]{2}{*}{$4-5$} & Vancomycin & & \\
\hline & 125 mg QDS & & \\
\hline \multirow[t]{2}{*}{$6-8$} & Metronidazole & $\rightarrow$ Vancomycin & \\
\hline & 400 mg TDS & $125 \mathrm{mg}$ QDS & \\
\hline \multirow[t]{2}{*}{9} & Vancomycin & + IV Metronidazole & \\
\hline & $125 \mathrm{mg}$ QDS & $500 \mathrm{mg}$ TDS & \\
\hline \multirow[t]{2}{*}{10} & Vancomycin & Vancomycin to 500 & + Metronidazole \\
\hline & $125 \mathrm{mg}$ QDS & $\mathrm{mg}$ QDS & $500 \mathrm{mg}$ TDS \\
\hline \multirow[t]{2}{*}{11} & Vancomycin & $\rightarrow$ Fidaxomycin & \\
\hline & $125 \mathrm{mg}$ QDS & 200 mg BD & \\
\hline \multirow[t]{2}{*}{12} & Metronidazole & $\rightarrow$ Vancomycin & \\
\hline & $400 \mathrm{mg}$ TDS & $125 \mathrm{mg}$ QDS & \\
\hline \multirow[t]{2}{*}{13} & Metronidazole & $\rightarrow$ Vancomycin & Vancomycin to 500 \\
\hline & $400 \mathrm{mg}$ TDS & $125 \mathrm{mg}$ QDS & $\mathrm{mg}$ QDS \\
\hline \multirow[t]{2}{*}{14} & Metronidazole & $\rightarrow$ Vancomycin & \\
\hline & $400 \mathrm{mg}$ TDS & $500 \mathrm{mg}$ QDS & \\
\hline
\end{tabular}

this was continued in all cases. 9 of the patients presented with acute severe colitis based on Truelove \& Witts Criteria.

Once the diagnosis of CDI was established metronidazole was given in 9 cases, and vancomycin in 5 (doses and any subsequent alterations shown in table 1).

Assessment with Travis criteria on day 3 indicated high chance of colectomy in 7 patients however none required surgical intervention. No patients received rescue biologics or faecal transplant. Median length of stay was 19 days (range 3169). One patient did not survive to discharge. Since index admission 4 were readmitted, and 6 have subsequently had their IBD therapy escalated.

Conclusions Managing CDI in those with co-existing IBD is clinically challenging. This case series highlights the lack of consensus on how this should be approached, even within a single health board. This suggests that a wider body of work is required to establish guidance and provide better outcomes.

\section{PTH-081 USTEKINUMAB TREATMENT STRATEGIES IN REFRACTORY CROHN'S DISEASE: REAL-WORLD EFFECTIVENESS DATA FROM A UK IBD CENTRE}

Richard Harris, Martin McDonnell, Marion Bettey, Louise Downey, David Young, Richard Felwick, Markus Gwiggner, Fraser Cummings*. University Hospital Southampton, UK

\subsection{6/gutjnl-2019-BSGAbstracts. 140}

Introduction Ustekinumab (UST) is a human IgG1 kappa mAb to the shared p40 subunit of IL-12 and IL-23 which are involved in TH1 and TH17 mediated pathways of Crohn's disease (CD) pathogenesis. NICE approved UST for CD in April 2017, but there is limited UK data on real-world effectiveness. We present clinical effectiveness, safety and drug persistence data from a complex UK cohort.

Methods This was a retrospective observation cohort study of all CD patients treated with UST outside clinical trials in a single UK IBD centre. Physician's global assessment (PGA) was recorded at baseline, post induction and 1 year. Primary 